\title{
Quantification of basal friction for technical and silvicultural glide-snow avalanche mitigation measures
}

\author{
T. Feistl ${ }^{1,2}$, P. Bebi ${ }^{1}$, L. Dreier ${ }^{1}$, M. Hanewinkel ${ }^{3}$, and P. Bartelt ${ }^{1}$ \\ ${ }^{1}$ WSL Institute for Snow and Avalanche Research SLF, Flüelastrasse 11, 7260 Davos Dorf, Switzerland \\ ${ }^{2}$ Technical University Munich (TUM), Engineering Geology and Hydrogeology, Arcisstrasse 21, 80333 Munich, Germany \\ ${ }^{3}$ University of Freiburg, Forestry Economics and Planning, Tennenbacherstrasse 4, 79106 Freiburg, Germany \\ Correspondence to: T. Feistl (thomas.feistl@slf.ch)
}

Received: 31 March 2014 - Published in Nat. Hazards Earth Syst. Sci. Discuss.: 29 April 2014

Revised: 24 September 2014 - Accepted: 26 September 2014 - Published: 7 November 2014

\begin{abstract}
A long-standing problem in avalanche engineering is to design defense structures and manage forest stands such that they can withstand the forces of the natural snow cover. In this way, glide-snow avalanches can be prevented. Ground friction plays a crucial role in this process. To verify existing guidelines, we collected data on the vegetation cover and terrain characteristics of 101 glide-snow release areas in Davos, Switzerland. We quantified the Coulomb friction parameter $\mu_{\mathrm{m}}$ by applying a physical model that accounts for the dynamic forces of the moving snow in the stauch zone. We investigated the role of glide length, slope steepness and friction in avalanche release. Our calculations revealed that the slope angle and slab length for smooth slopes correspond to the technical guidelines for defense structure distances in Switzerland. Artificial defense structures, built in accordance with guidelines, prevent glide-snow avalanche releases, even when the terrain is smooth. Slopes over $40 \mathrm{~m}$ in length and $45^{\circ}$ in steepness require a ground friction of $\mu_{\mathrm{m}}=0.7$ corresponding to stumps or tree regeneration to ensure protection. Forest management guidelines that define maximum forest gap sizes to prevent glide-snow avalanche release neglect the role of surface roughness and therefore underestimate the danger on smooth slopes.
\end{abstract}

\section{Introduction}

Full-depth, glide-snow avalanches are common events on the steep, smooth slopes of the European Alps (In der Gand and Zupančič, 1966; Höller, 2014). Although these slides have relatively small release areas, they endanger roads, railways and other infrastructure. Because glide-snow avalanches are difficult to predict (Dreier, 2013), hazard engineers rely on mitigation measures to stabilize the snow cover and prevent glide-snow avalanches from starting. These measures include both technical defense structures and forests (Margreth, 2007; Höller, 2012). A critical problem for decision makers is to define potential release areas in real terrain and understand how terrain and vegetation characteristics influence release and can be managed to defend against glidesnow avalanche hazard.

The mechanics of glide-snow avalanches involve two principle components: the compressive strength of the stauchwall and the frictional properties of the ground (In der Gand and Zupančič, 1966; Häfeli, 1967; McClung, 1975; Bartelt et al., 2012). Glide-snow avalanches typically occur when water accumulates on the snow-soil interface, either by melting (because of a warm soil surface) or by meltwater penetration through the snow cover (In der Gand and Zupančič, 1966; Mitterer et al., 2011). As the ground friction decreases because of the meltwater, the lost frictional forces must be taken up in the tensile or compressive zone of the snow cover; otherwise, it begins to glide (Fig. 1). Typically, the snow cover breaks first in the tensile zone, and a glide crack (a so-called Fischmaul) opens. This causes an additional redistribution of stress within the snow cover, and leads to a fragile stability governed by the strength of the compressive zone. This zone is termed the stauchwall (Lackinger, 1987; Bartelt et al., 2012). The stauchwall is fixed to the ground, either because the basal surface is rough, or because the slope is flatter, leading to large compressive stresses. Any obstacles, such as trees, will help to stabilize the snow cover by 


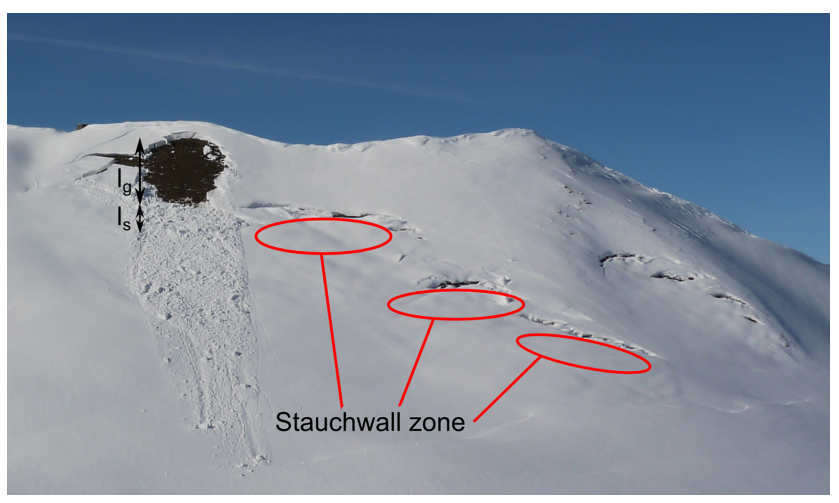

Figure 1. Opening of glide cracks (Fischmaul) near Davos. The left slope released, probably because the slope is steeper than the right part. $l_{\mathrm{g}}$ and $l_{\mathrm{s}}$ denote the observed slab length and the stauchwall length.

absorbing the additional stress. The distance between obstacles in large part determines the stress redistribution: if the distances are too great, the natural strength of the snow cover will be overcome, and snow slides will result (de Quervain, 1979; Höller, 2004). A key parameter in the mitigation of glide-snow avalanches is therefore the distance between defense structures and the allowable forest clearing size. Different approaches have been addressed to define distances between defense structures and maximum forest gap sizes. The Swiss guidelines on sustainable management of protective forests (NaiS) (Frehner et al., 2005), for example, are based on a statistical evaluation of data mostly gained in a field campaign in Switzerland from 1985 to 1990 (Gubler and Rychetnik, 1991; Meyer-Grass and Schneebeli, 1992). Statements on possible avalanche formation as a function of slope angle and gap length could be made, taking ground roughness qualitatively into account (Frehner et al., 2005). These guidelines were successfully applied in the past by foresters. Leitinger et al. (2008) developed a spatial snow-glide model based on data of two study areas in Austria and Italy. It takes slope angle, surface roughness, slope aspect, winter precipitation and forest stand characteristics into account. Likewise, the technical guidelines for avalanche prevention structures in release areas in Switzerland are based on calculations of the pressure that a slab exerts on an avalanche prevention bridge (de Quervain and Salm, 1963; Margreth, 2007). Slope angle, snow depth and the Coulomb friction of the snow on the ground are taken into account.

Although the relationship between slab length and slope angle at which glide-snow avalanches release is well understood (Fiebiger, 1978; Imbeck, 1984; Imbeck and MeyerGrass, 1988; Gubler and Rychetnik, 1991; Meyer-Grass and Schneebeli, 1992; Leitinger et al., 2008), the important role of ground roughness remains an unknown parameter. Ground friction dictates the force redistribution and therefore the loading on the stauchwall (In der Gand and Zupančič,
1966; McClung, 1975; Höller, 2004; Bartelt et al., 2012). Vegetation can increase the ground roughness significantly (de Quervain, 1979; Fiebiger, 1978; Newesely et al., 2000; Höller, 2001; Leitinger et al., 2008; Schneebeli and Bebi, 2004; Weir, 2002). Although all authors agree that glidesnow avalanche activity is retarded by dense forest stands, the quantification of basal friction as a function of vegetation structure is missing.

In this paper, we aim to combine a physical ground friction-stauchwall model with data on glide-snow avalanche release areas to quantify the role of technical and silvicultural avalanche protection measures. To this end, we collected and analyzed data of the characteristic vegetation cover, terrain and snow characteristics of glide-snow avalanche release areas on the Dorfberg, near Davos, Switzerland. We compare the glide-snow avalanche data with model results and test if existing guidelines are in accordance with our measurements. As the glide-snow avalanche model includes the important role of ground roughness - which is strongly influenced by the vegetation cover - we are able to link the observed terrain roughness and ground vegetation to specific Coulomb friction values. Finally, we attempt to answer the questions of where, when and what elements of terrain roughness are most appropriate for glide-snow avalanche prevention.

\section{Methods}

\subsection{Observed glide-snow avalanche release areas}

Glide-snow avalanches are observed every season on the Dorfberg, above Davos, Switzerland, and were documented via time lapse photography in the winters of 2011/2012 and 2012/2013 (van Herwijnen and Simenhois, 2012). Their occurrence depends on meteorological conditions such as temperature, snow depth, snow stratification and ground temperature (Dreier, 2013; Dreier et al., 2013), but their location in the terrain is almost similar each year. Dreier (2013) mapped the release zones according to the photos (see Fig. 2). These photos were not georeferenced, and a small uncertainty concerning the location of the release areas in the terrain exists, but we suppose the error to be relatively small. We performed a field campaign in autumn 2013 where we collected data on the characteristic vegetation cover, vegetation height $h_{\mathrm{v}}$, distance to the next obstacle and terrain characteristics of 101 glide-snow avalanche release areas on the Dorfberg. The compaction of vegetation due to the snow cover weight was documented in a second field campaign in February 2014.

The south-to-east-facing slope below the Salezer Horn $(2536 \mathrm{~m})$ covers $200 \mathrm{ha}$. The elevation of the observed release areas ranges from 1700 to $2300 \mathrm{~m}$ a.s.l. Grassy slopes, shrubs and forest alternate with stones and small rock walls. We calculated the mean slope angles $\alpha$ and slab lengths $l_{\mathrm{g}}$ of all avalanche release areas using ArcGIS. The release height was estimated with the snow depth $h_{\mathrm{s}}$ measured at 


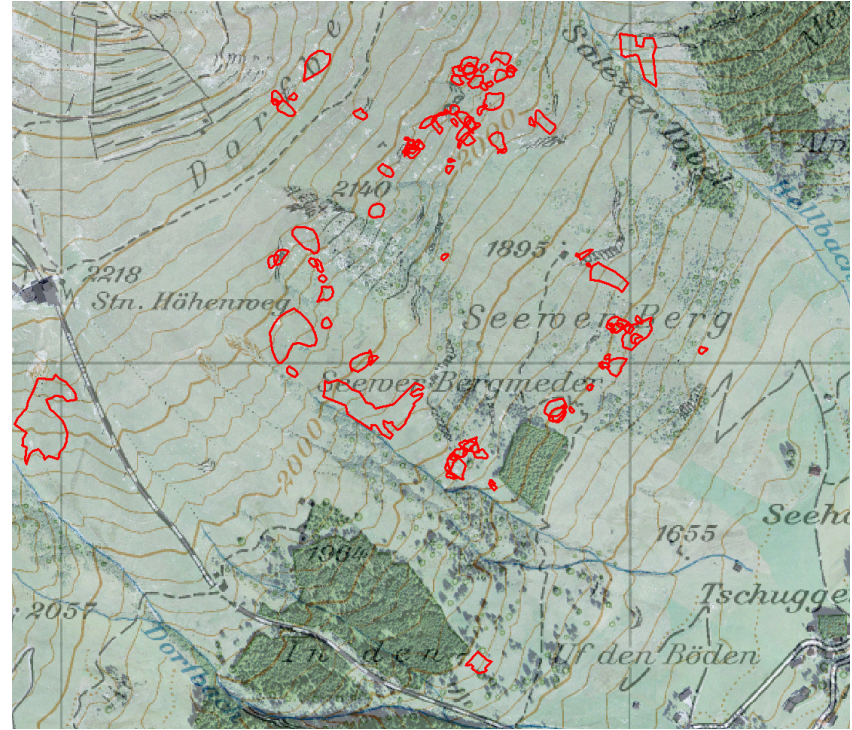

Figure 2. Glide-snow avalanche release zones on the Dorfberg, Davos (Swissimage ${ }^{\circledR}$, DV 033594, 2013).

the meteorological station in Davos. The station is situated at a lower elevation (1560 ma.s.1.), but is not exposed to the sun. The snow depth on the Dorfberg and therefore the release height of the glide-snow avalanches resemble the snow depth measured at the meteorological station in the investigated winters.

We documented the typical vegetation cover of the 101 release areas (Fig. 3), and found four characteristic types of vegetation:

\section{1. long grass (Calamagrostis villosa)}

2. short grass (Nardion spp.)

\section{3. low dwarf shrubs (Ericaceae, Vaccinuium, Empetrum)}

4. strong lignified shrubs (Rhododendron, Juniperus).

No avalanches were observed in forested terrain. We recorded the dominating vegetation species, if more than one vegetation type was present in a single release area. The vegetation height $h_{\mathrm{v}}$ was measured in November 2013 and February 2014 (Fig. 4). Our first field study took place in autumn; therefore, this vegetation height represents the surface that the first snow fell on. In February 2014, the vegetation heights were measured below the snow cover at representative locations on the Dorfberg. We observed a mean height of long compacted grass $h_{\mathrm{v}}<1 \mathrm{~cm}$, in contrast to short upright grass with $h_{\mathrm{v}}=3 \mathrm{~cm}$, low dwarf shrubs with $h_{\mathrm{v}}=4 \mathrm{~cm}$ and strong lignified shrubs with $10 \mathrm{~cm}<h_{\mathrm{v}}<20 \mathrm{~cm}$ (Fig. 4). The snow cover of depth $h_{\mathrm{s}}=0.5 \mathrm{~m}$ compacted long grass to one tenth of the height in autumn. Short grass, low dwarf shrubs and strong lignified shrubs were compacted to one fourth of their original height.

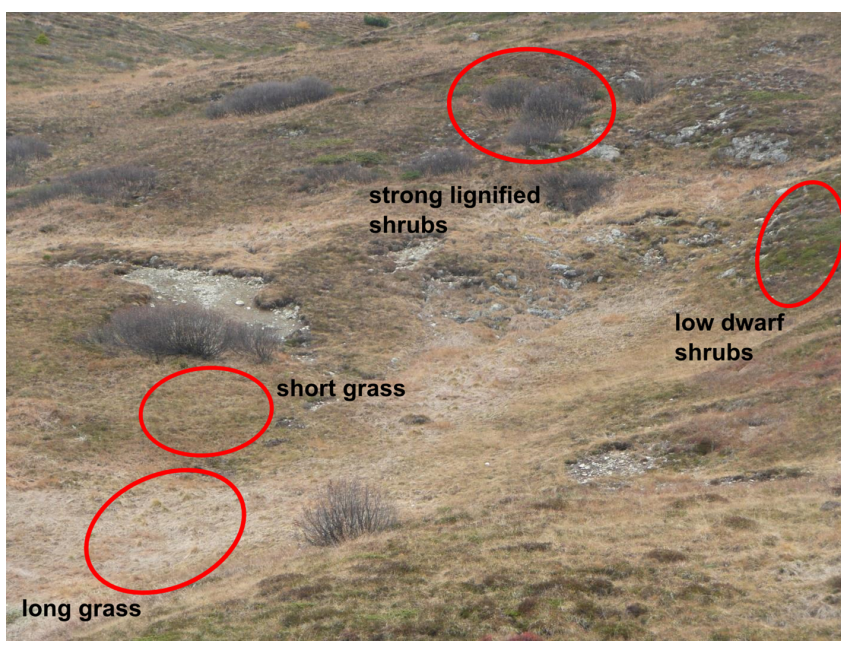

Figure 3. Different vegetation types were observed in our field campaign. The main types were long grass, short grass, low dwarf shrubs and strong lignified shrubs.

As topography contributes to roughness, we assume the underlying terrain of the release areas to play an important role in glide-snow avalanche release. Therefore, we documented the dominating terrain types and their height $h_{\mathrm{t}}$ for each release area. Typical features we found were smooth steps, rocks and ridges. We performed a Mann-Withney $U$ test in order to test if these different vegetation and terrain types in release areas correlate with slope angle, slab length and snow depth.

We parameterized surface roughness using the measured terrain irregularity heights $h_{\mathrm{t}}$ and vegetation heights $h_{\mathrm{v}}$. This allowed us to relate the observed heights to the calculated friction parameter $\mu_{\mathrm{m}}$. The heights $h_{\mathrm{v}}$ and $h_{\mathrm{t}}$ are assigned values characteristic of the observed vegetation and terrain types. This is necessary in order to transfer the model results to other field locations.

\subsection{Selection of avalanches with stauchwall}

We selected events where we assume the snow cover below the release area to be fixed to the ground, the so-called stauchwall. The mechanical stauchwall model (Sect. 2.3) is applicable for these events. A flatter slope, higher surface roughness or an obstacle (Fig. 5) below the release area are cases where a fixed stauchwall is probable. Several events without a stauchwall were neglected in further studies. In particular, events with either a drop or with a steeper slope below the release area (Fig. 6) were disregarded. These events were found by comparing the slope angle of the release areas $\alpha$ with the slope angle of the areas below $\beta$. If $\alpha<\beta$, we assume no stauchwall to be present. Out of 101 glide-snow avalanches, 67 events were considered with a stauchwall. Of these 67 events, 31 released on compacted 


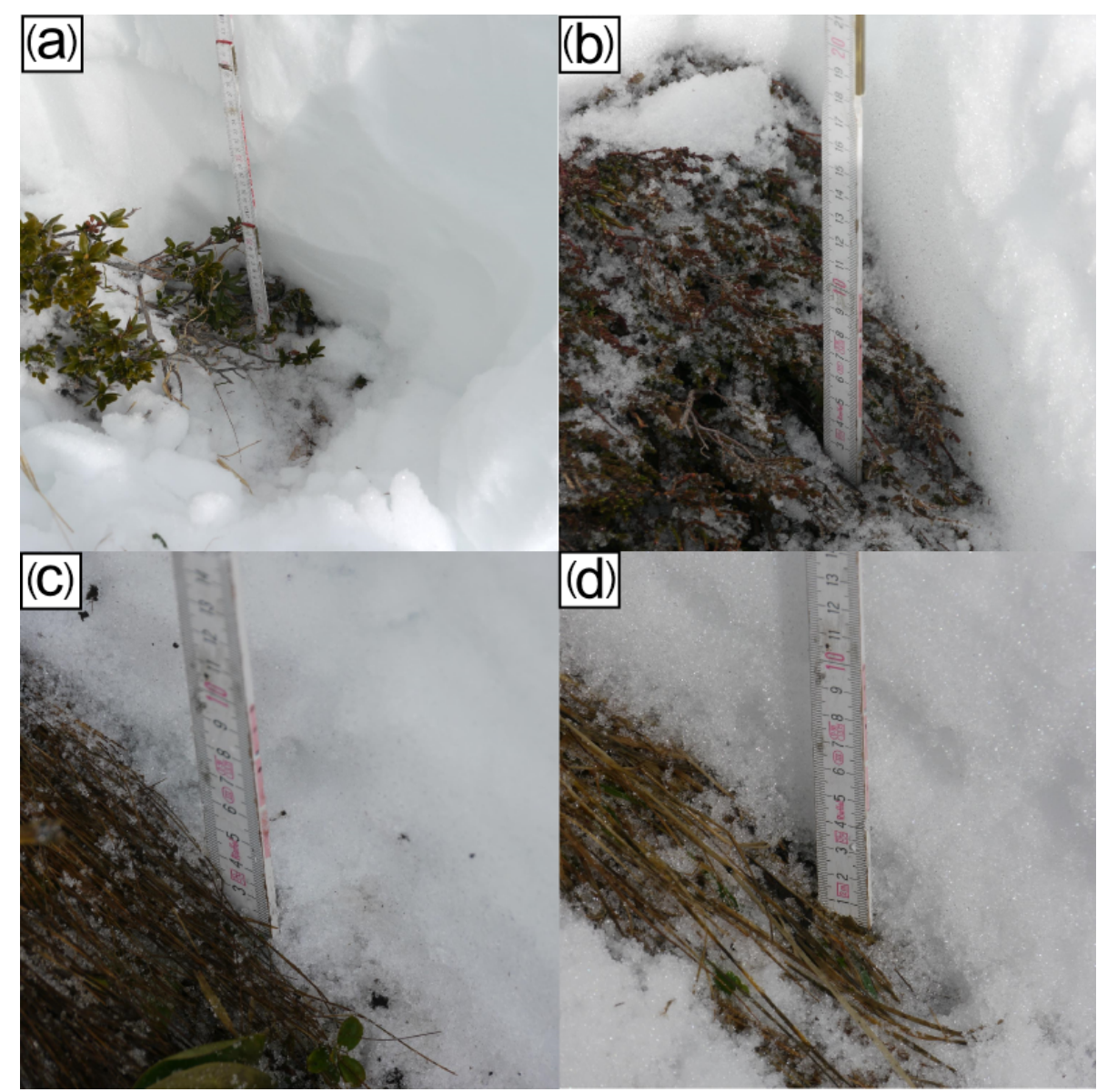

Figure 4. Vegetation below the snow cover. Vegetation heights $h_{\mathrm{v}}$ are lower in winter than in autumn: 10-20 cm for strong lignified shrubs (a), $4 \mathrm{~cm}$ for low dwarf shrubs (b), $3 \mathrm{~cm}$ for short grass (c) and less than $1 \mathrm{~cm}$ for long grass (d).

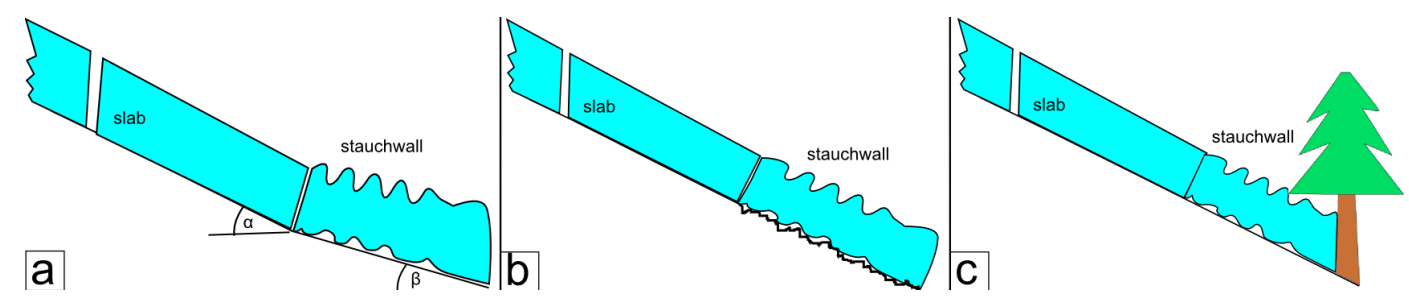

Figure 5. Cases where a stauchwall forms: in (a), the area below the release zone is flatter than the release area. The rougher surface below the release zone fixes snow to the ground (b), and a tree can be an effective obstacle stabilizing the snow cover below the release area (c).

long grass, 4 on upright short grass, 31 on low dwarf shrubs and 1 on strong lignified shrubs.

Vegetation cover and terrain both contribute to ground roughness. We defined three combined categories (see Sect. 3.1) to enable a simplified classification:

1. smooth terrain covered with long compacted grass;

2. smooth terrain covered with short upright grass or low dwarf shrubs; and

3. rocky or stepped terrain covered with shrubs.
Only avalanches with stauchwall were considered for this categorization. Long compacted grass always had smooth terrain underneath. We assume this combination of long grass and smooth terrain to form the surface with the lowest friction. Short grass or low dwarf shrubs on smooth terrain were defined as the second category, and the third category was shrubs on steps or rocks. On stepped terrain or on rocky slopes, we did not find any grass-dominated vegetation. 


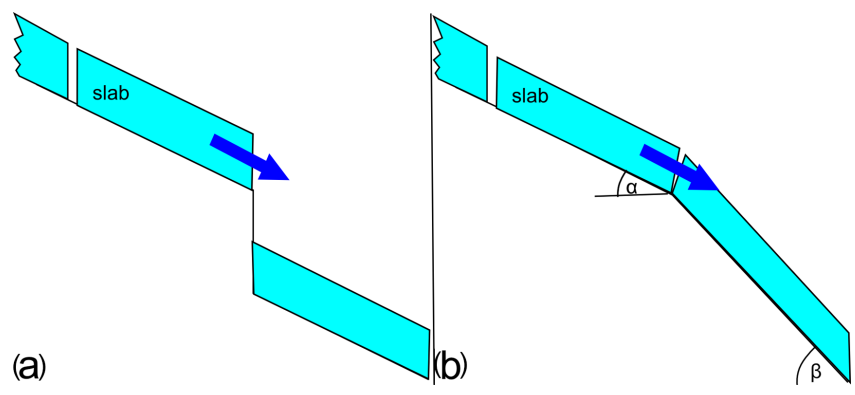

Figure 6. Cases where no stauchwall forms: either there is a terrain drop (a) or the area below the release is steeper than the release area (b).

\subsection{Mechanical stauchwall model}

To predict glide-snow avalanche release, we apply the twodimensional visco-elastic continuum model of Bartelt et al. (2012). The model divides the snow cover into two regions: the sliding zone and the stauchwall (Fig. 7). The sliding zone has length $l_{\mathrm{m}}$; the stauchwall has length $l_{\mathrm{s}}$ and is fixed to the ground. We assume a snow cover with depth $h_{\mathrm{s}}$ and a homogenous density $\rho$. Therefore, the total mass per unit width of the slab is $m=\rho h_{\mathrm{s}} \cos \alpha l_{\mathrm{m}}$. The snow cover starts to slide downwards once the frictional force on the ground can not withstand the gravitational force of the snowpack, and a tensile crack opens at the crown. Static equilibrium is lost, and the tensile force at the crown must be transferred to the sliding zone and the stauchwall. The avalanche releases if a critical strain rate is reached. It is possible that the lost force is balanced entirely by an increase in shear stress at the base of the snow cover. In this case, no avalanche will release, but this scenario requires high friction $\mu_{\mathrm{m}}$ to transfer the lost tensile force to the ground. Moreover, the driving force and the friction resistance are in balance:

$m g_{x}=\mu_{\mathrm{m}} m g_{z}$,

where $g_{x}$ and $g_{z}$ are the gravitational accelerations in the slope parallel and normal directions, respectively. These depend on the slope angle $\alpha$. It is also possible that the lost force is taken up by the stauchwall. In this case, there is an out-of-balance stress $\sigma$ that must be resisted by the stauchwall:

$m \dot{u}(t)=m g_{x}-\mu_{\mathrm{m}} m g_{z}-\sigma(t) h_{\mathrm{s}} \cos \alpha$,

where $u(t)$ is the displacement velocity of the slab. Because snow is a visco-elastic material, the stauchwall resisting stress $\sigma$ is time dependent. A simple Burger model is used to calculate the resisting action of the stauchwall:

$\ddot{\sigma}(t)+\left[\frac{E_{m}}{\eta_{m}}+\frac{E_{m}}{\eta_{k}}+\frac{E_{k}}{\eta_{k}}\right] \dot{\sigma}(t)+\left[\frac{E_{m} E_{k}}{\eta_{m} \eta_{k}}\right] \sigma(t)$

$=\frac{E_{m}}{2 l_{\mathrm{s}}} \dot{u}(t)+\frac{E_{m} E_{k}}{2 \eta_{k} l_{\mathrm{s}}} u(t)$.

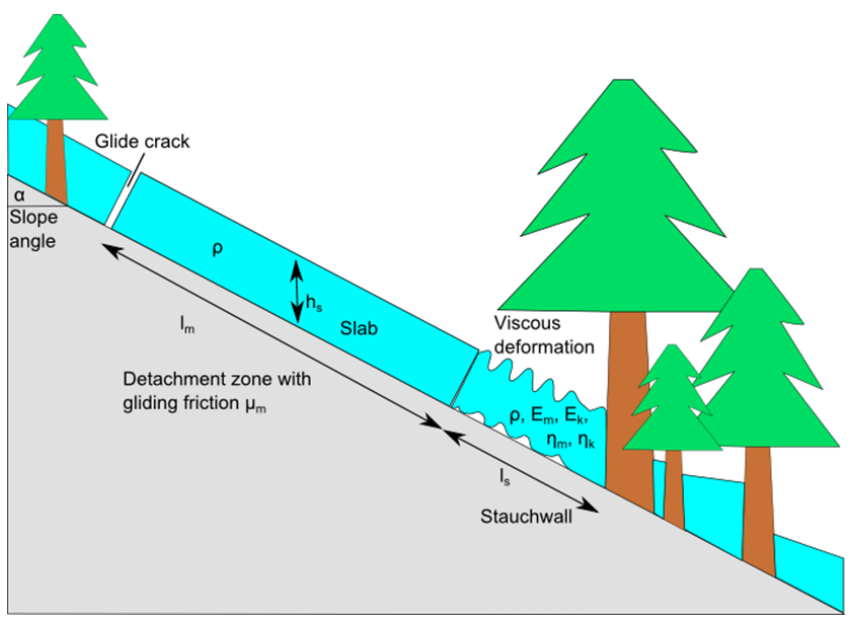

Figure 7. Model description: a slab with length $l_{\mathrm{m}}$, snow density $\rho$ and snow depth $h_{\mathrm{s}}$ starts to glide on a slope with angle $\alpha$. A glide crack opens and the weight of the slab $m$ is balanced by the friction of the snow on the ground $\mu_{\mathrm{m}}$ and the stauchwall with length $l_{\mathrm{s}}$, snow density $\rho$ and material parameters $E_{k}, E_{m}, \eta_{k}$, and $\eta_{m}$.

The visco-elastic constants $\left(E_{\mathrm{m}}, E_{\mathrm{k}}, \eta_{\mathrm{m}}, \eta_{\mathrm{k}}\right)$ are density and temperature dependent (Von Moos et al., 2003; Scapozza and Bartelt, 2003). Equations (2) and (3) are a system of two coupled ordinary differential equations that can be solved numerically. Numerical solutions are presented in Bartelt et al. (2012). The model predicts the strain rate $\dot{\epsilon}=u / 2 l_{\mathrm{s}}$ in the stauchwall. The total strain $E$ and therefore the total deformation are calculated by summing the strain rates at every calculation step with length $\Delta t: E(t+\Delta t)=\epsilon(t)+\dot{\epsilon} \Delta t$. When the strain rates exceed a critical value, we consider the stauchwall to fail, and an avalanche is released.

\subsection{Technical guidelines}

For further analysis, we refer to the technical guidelines for avalanche prevention structures in release areas in Switzerland (Margreth, 2007), the Swiss guidelines on sustainable management of protective forests NaiS (Frehner et al., 2005), and the Austrian norm for avalanche prevention structures (Austrian Standard Institute, 2011). These guidelines specify the maximum allowable length between defense structures and the maximum allowable length of forest clearings. For clarity, we denote these allowable lengths as $l_{\mathrm{d}}$ and $l_{\mathrm{f}}$, respectively. The stauchwall is within these lengths. The guidelines require knowledge of the ground friction, which we have designated $\mu_{\mathrm{d}}$ for the guidelines. The distance between prevention bridges is calculated according to $l_{\mathrm{d}}=\frac{2 \tan \alpha}{\tan \alpha-\mu_{\mathrm{d}}} h_{\mathrm{s}}$. For example, the allowable defense structure distance $l_{\mathrm{d}}$ in Switzerland is calculated with friction values of $0.5 \leq \mu_{\mathrm{d}} \leq$ 0.6 . Therefore, $l_{\mathrm{d}}\left(\mu_{\mathrm{d}}, \alpha\right)$ and $l_{\mathrm{f}}\left(\mu_{\mathrm{d}}, \alpha\right)$ as the guidelines depend on the slope angle $\alpha$. Although the technical and forest guidelines are based on different approaches, the aim of all the guidelines is similar: within the distances $l_{\mathrm{d}}\left(\mu_{\mathrm{d}}, \alpha\right)$ 
Table 1. The observed vegetation types on the Dorfberg. Mean vegetation height $h_{\mathrm{V}}$ in autumn and winter, slope angle $\alpha$, slab length $l_{\mathrm{g}}$ and a photo of a typical example case are added.

\begin{tabular}{|c|c|c|c|c|}
\hline Vegetation type & $\begin{array}{l}\text { Long } \\
\text { compacted } \\
\text { grass }\end{array}$ & $\begin{array}{l}\text { Short } \\
\text { upright } \\
\text { grass }\end{array}$ & $\begin{array}{l}\text { Low } \\
\text { dwarf } \\
\text { shrubs }\end{array}$ & $\begin{array}{l}\text { Strong } \\
\text { lignified } \\
\text { shrubs }\end{array}$ \\
\hline Number of avalanches & 45 & 6 & 49 & 1 \\
\hline $\operatorname{Mean} \alpha\left(^{\circ}\right)$ & 35 & 36 & 39 & 35 \\
\hline Mean $l_{\mathrm{g}}(\mathrm{m})$ & 26 & 42 & 28 & 38 \\
\hline Mean $h_{\mathrm{V}}(\mathrm{m})$ in autumn & 0.10 & 0.13 & 0.14 & 0.5 \\
\hline Mean $h_{\mathrm{v}}(\mathrm{m})$ in winter & 0.01 & 0.03 & 0.04 & 0.15 \\
\hline
\end{tabular}

or $l_{\mathrm{f}}\left(\mu_{\mathrm{d}}, \alpha\right)$, no avalanche should release. On the Dorfberg, we have measured the distance between the fracture crown and the stauchwall; we denote the observed lengths as $l_{\mathrm{g}}$. We have documented the terrain features and vegetation associated with each $l_{\mathrm{g}}$. Furthermore, we have quantified the mean slope angle of each slide observed in the field. That is, we have $l_{\mathrm{g}}\left(\mu_{\mathrm{m}}, \alpha\right)$. If the guidelines are correct, we should have

$l_{\mathrm{d}}\left(\mu_{\mathrm{d}}, \alpha\right) \leq l_{\mathrm{g}}\left(\mu_{\mathrm{m}}, \alpha\right)+l_{\mathrm{s}}$

and

$l_{\mathrm{f}}\left(\mu_{\mathrm{d}}, \alpha\right) \leq l_{\mathrm{g}}\left(\mu_{\mathrm{m}}, \alpha\right)+l_{\mathrm{s}}$,

where the stauchwall length is denoted $l_{\mathrm{s}}$ and added to the measured slab length $l_{\mathrm{g}}$. These comparisons should also hold for the mechanical model. To distinguish between measured and modeled slab length, we denote the modeled slab length by $l_{\mathrm{m}}$. That is,

$l_{\mathrm{d}}\left(\mu_{\mathrm{d}}, \alpha\right) \leq l_{\mathrm{m}}\left(\mu_{\mathrm{m}}, \alpha\right)+l_{\mathrm{s}}$

and

$l_{\mathrm{f}}\left(\mu_{\mathrm{d}}, \alpha\right) \leq l_{\mathrm{m}}\left(\mu_{\mathrm{m}}, \alpha\right)+l_{\mathrm{s}}$.

We calculated the critical slab lengths (the slab lengths at failure $l_{\mathrm{m}}$ ) for all slope angles mentioned in the guidelines. Different friction parameters $\mu_{\mathrm{m}}$ were applied in the model calculations. By comparison, we could quantify the friction values we observed in the field. In the model calculations, we tested different snow densities and snow depths to investigate the role these parameters had in strain rates and therefore glide-snow avalanche formation.

\section{Results and discussion}

\subsection{Results of field observations, $l_{\mathrm{g}}\left(\mu_{\mathrm{m}}, \alpha\right)$}

Most releases in the Dorfberg study area were found on long grass (45 avalanches) and on low dwarf shrub vegetation (49 avalanches), whereas only a few avalanches released on vegetation categories "short grass" and strong "lignified shrubs" (Table 1). Categories "short grass" and "low dwarf shrubs" had comparable vegetation heights $h_{\mathrm{v}}$ (Table 1). We subsequently combined these two categories in our data analysis. The mean vegetation height of long grass was $10 \mathrm{~cm}$, whereas the mean vegetation height of short grass was $13 \mathrm{~cm}$, of low dwarf shrubs $14 \mathrm{~cm}$ and of strong lignified shrubs $50 \mathrm{~cm}$. These values were measured before the first snowfall. Below the snow cover (measurements taken in February 2014), the heights decreased to $h_{\mathrm{v}}<1 \mathrm{~cm}$ for long grass, $h_{\mathrm{v}}=3 \mathrm{~cm}$ and $h_{\mathrm{v}}=4 \mathrm{~cm}$ for short grass and low dwarf shrubs, and $10 \mathrm{~cm}<h_{\mathrm{v}}<20 \mathrm{~cm}$ for strong lignified shrubs. We also combined different terrain types according to their measured irregularity heights $h_{\mathrm{t}}$ (Table 2). Irregularities in smooth terrain and ridges had a mean height of approximately $20 \mathrm{~cm}$, in contrast to stepped and rocky terrain, with approximately $30 \mathrm{~cm}$. We note that in autumn, only $5 \mathrm{~cm}$ separates the vegetation types, and $10 \mathrm{~cm}$ separates the two terrain classes. Below the snow cover, the differences are even smaller. This is an indication that small height variations can lead to a large difference in surface friction.

The release of glide-snow avalanches on the Dorfberg depended strongly on surface characteristics. Releases occurred in steeper terrain in areas with shrubs compared to areas with long grass (Mann-Whitney $U$ test, $p=0.008$ ) and in areas with terrain type "smooth" compared to other terrain types (79 events out of 101). The combination of vegetation and terrain categories led to clear correlations between 
Table 2. The observed terrain on the Dorfberg. Mean slope angle $\alpha$, slab length $l_{\mathrm{g}}$, terrain height $h_{\mathrm{t}}$ and a photo of a typical example case are added. Note the high number of smooth terrain cases.

\begin{tabular}{lllll}
\hline Terrain & Ridge & Smooth & Steps & Rocks \\
\hline Number of avalanches & 1 & 79 & 9 & 12 \\
Mean $\alpha\left(^{\circ}\right)$ & 36 & 37 & 38 & 40 \\
Mean $l_{\mathrm{g}}(\mathrm{m})$ & 40 & 26 & 36 & 34 \\
Mean $h_{\mathrm{t}}(\mathrm{m})$ & 0.15 & 0.19 & 0.31 & 0.32 \\
& & & & \\
& & & & \\
& & & & \\
Photo & & & &
\end{tabular}

glide-snow avalanches and surface characteristics. This suggests the importance of basal properties. For example, we found that glide-snow avalanches can release on relatively flat slopes, and had the shortest slab lengths if the terrain was smooth and was covered with long grass. Higher slope angles and longer slab lengths were observed for the slopes covered with short grass or shrubs growing on smooth terrain. The highest slope angles and release lengths were necessary for cases where the terrain was rocky or stepped and covered with shrubs. In this case, the mean slope angles and slab lengths increased.

Snow depth $h_{\mathrm{s}}$ (at the release) correlated weakly with the slab length $l_{\mathrm{g}}$ (Fig. 8). Avalanches with a release length of $l_{\mathrm{g}}>50 \mathrm{~m}$ were observed only for snow depths of more than $1 \mathrm{~m}, h_{\mathrm{s}}>1 \mathrm{~m}$. Note that slope angle $\alpha$ and snow depth $h_{\mathrm{s}}$ could not be correlated. The mean snow depth was slightly higher for short grass, low dwarf shrubs and strong lignified shrubs $\left(h_{\mathrm{s}}=94 \mathrm{~cm}\right)$ than for long grass $\left(h_{\mathrm{s}}=84 \mathrm{~cm}\right)$. Snow depth has an influence on the mean vegetation height, as vegetation is compressed by the snow mass (Table 1, Fig. 4). Long grass is already compressed with a relatively small load. However, shrubs need more weight for a similar effect. We observed glide-snow avalanche release on less steep slopes covered with low dwarf shrubs only for snow depths $h_{\mathrm{s}}>1 \mathrm{~m}$. No such effect was found for slopes covered with grass.

\subsection{Results of model calculations $l_{\mathrm{m}}\left(\mu_{\mathrm{m}}, \alpha\right)$}

We performed a series of model calculations to establish a correlation between strain rate, slab length, slope angle and ground friction. We studied the influence of ground roughness $\mu_{\mathrm{m}}$ on slab length $l_{\mathrm{m}}$ and slope angle $\alpha$ by modeling the resistance and failure of the stauchwall (Sect. 2.3). We kept the material parameters of snow $\left(E_{\mathrm{m}}=1.5 \times 10^{8} \mathrm{~Pa}, E_{\mathrm{k}}=\right.$ $\left.1.5 \times 10^{7} \mathrm{~Pa}, \eta_{\mathrm{m}}=1.4 \times 10^{9} \mathrm{~Pa} s, \eta_{\mathrm{k}}=2.5 \times 10^{6} \mathrm{Pas}\right)$ constant and defined a critical strain rate in compression $(\dot{\epsilon}=$ $0.01 \mathrm{~s}^{-1}$ ) that leads to the collapse of the stauchwall. The ma-

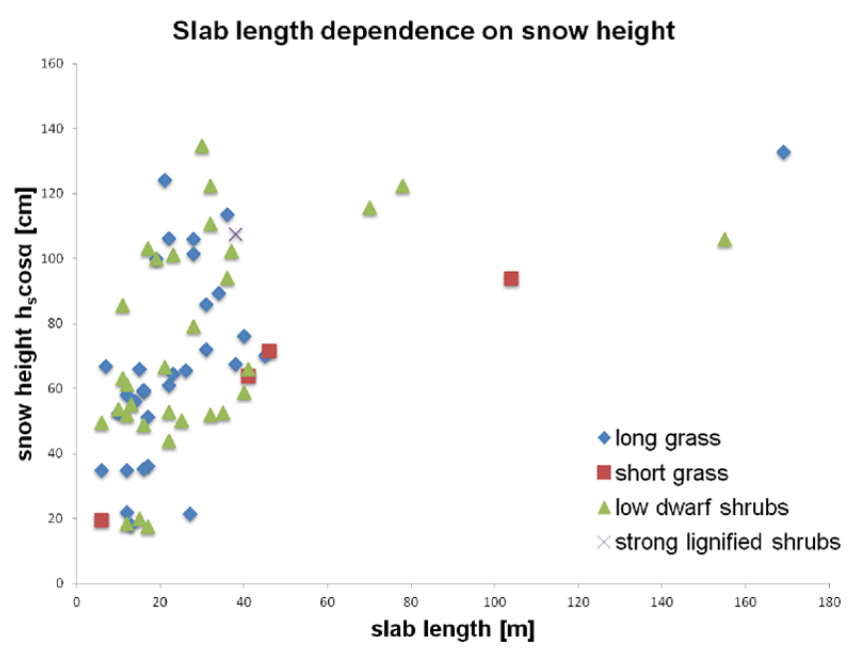

Figure 8. Slab length and snow height correlate weakly (Pearson coefficient of correlation squared: $R^{2}=0.25$ ). The longest slabs $l_{\mathrm{g}}$ were observed for snow heights $h_{\mathrm{s}} \cos \alpha$ greater than $90 \mathrm{~cm}$. Whereas short release areas (up to $50 \mathrm{~m}$ ) are possible for any snow height, long slabs are characteristic of large snow heights. Here, we only look at the 67 events where we assume a stauchwall to be present.

terial parameters and the critical strain rate were defined according to the work of Von Moos et al. (2003), Scapozza and Bartelt (2003) and Bartelt et al. (2012). Model results for different slope angles, slab lengths and friction parameter values are depicted in Fig. 9. We varied density $\rho$ and the stauchwall length $l_{\mathrm{s}}$, which depends on the snow depth $h_{\mathrm{s}}$. We found friction values between $\mu_{\mathrm{m}}=0.33$ and $\mu_{\mathrm{m}}=0.81$ for a density $\rho=300 \mathrm{~kg} \mathrm{~m}^{-3}$ and a stauchwall length $l_{\mathrm{s}}=2 \mathrm{~m}$. The lowest values are necessary for a slope angle $\alpha=30^{\circ}$ and slab length $l_{\mathrm{m}}=30 \mathrm{~m}$ to prevent the stauchwall from failing. The highest values are necessary for a slope angle $\alpha=45^{\circ}$ and a slab length $l_{\mathrm{m}}=60 \mathrm{~m}$. Clearly, the calculated 
Threshold values of friction, slope angle and slab length

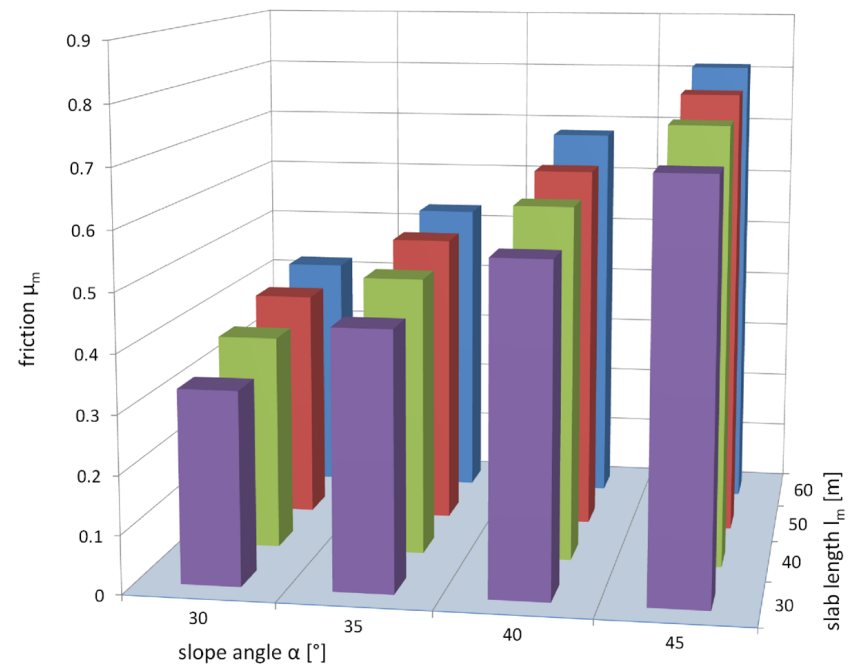

Figure 9. Three-dimensional plot showing combinations of friction $\mu_{\mathrm{m}}$, slope angle $\alpha$ and slab length $l_{\mathrm{m}}$ for a critical strain rate $\dot{\epsilon}=0.01 \mathrm{~s}^{-1}$. The higher the slope angle, the higher the friction $\mu_{\mathrm{m}}$ must be to prevent a failure of the stauchwall. The larger the slab length $l_{\mathrm{m}}$, the larger the friction $\mu_{\mathrm{m}}$ must be to prevent failure.

slab lengths and slope angles at failure depend strongly on the friction parameter $\mu_{\mathrm{m}}$.

We investigated the role of snow density $\rho$ and snow depth $h_{\mathrm{S}}$ in the model results. We kept the slab length $l_{\mathrm{m}}$ and slope angle $\alpha$ constant. The model results revealed that a change in density of $\Delta \rho=50 \mathrm{~kg} \mathrm{~m}^{-3}$ needs a corresponding change in the friction parameter $\Delta \mu_{\mathrm{m}}$ of approximately 0.03 . Therefore, we find that higher density snowpacks require higher surface roughness in order for the stauchwall to withstand the higher pressure. Moreover, the process of densification by snow settling coupled with meltwater (decrease of $\mu_{\mathrm{m}}$ ) could be a critical combination leading to glide-snow avalanche release. Thus, the process of densification, which can stabilize the high winter snowpack, must not automatically lead to a reduction in glide-snow avalanche activity. For further studies, we kept the density constant, $\rho=250 \mathrm{~kg} \mathrm{~m}^{-3}$.

The pressure on the stauchwall also depends on the snow depth $h_{\mathrm{s}}$. However, snow depth also increases the strength of the stauchwall, and therefore the snow depth $h_{\mathrm{s}}$ has no direct effect on glide-snow avalanche release. This result is reflected in Eq. (2). In the model calculations, we assumed the stauchwall length to be twice as long as the snow depth. This assumption is based on observations, as shown for example in Fig. 1, in which the stauchwall length can be discerned as the zone with wavelike perturbations on the surface of the snowpack. No systematic measurements exist, since the stauchwall is typically destroyed during an avalanche release. We therefore varied the snow depth $h_{\mathrm{s}}$ and the stauchwall length $l_{\mathrm{s}}$, respectively, and found that greater depth snow covers are more stable on smooth slopes. This

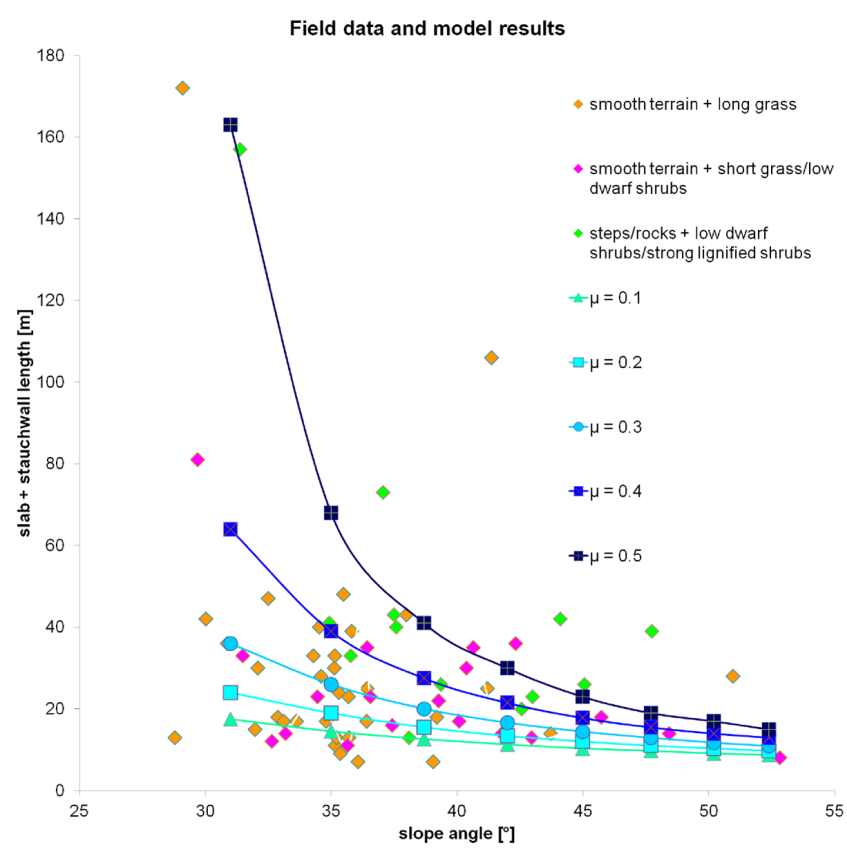

Figure 10. Comparison of glide-snow avalanche release length and stauchwall $l_{\mathrm{g}}+l_{\mathrm{S}}$ from the Dorfberg with model results. The graph shows slope angle against slab length of the 67 avalanches with a stauchwall. We divided the data into three roughness categories: smooth terrain + long grass, smooth terrain + short grass or shrubs and stepped or rocky terrain + shrubs.

result suggests that snow cover stability is relatively robust to changes in snow depth. Moreover, the model results are in accordance with the observations, which show a similar trend (Fig. 8). For example, we found very little correlation between avalanche release and snow depth: glide-snow avalanches can have both large and small fracture heights.

\subsection{Comparison of guidelines, model results and field observations}

We compared observed slab lengths $l_{\mathrm{g}}\left(\mu_{\mathrm{m}}, \alpha\right)$ from the Dorfberg with our calculated model results $l_{\mathrm{m}}\left(\mu_{\mathrm{m}}, \alpha\right)$ (Fig. 10). For this analysis, we only used data of the events with a stauchwall (see Sect. 2.2). To be able to compare these to guidelines, the stauchwall length $l_{\mathrm{s}}$ was added to the observed slab length $l_{\mathrm{g}}+l_{\mathrm{s}}$ and the modeled slab lengths $l_{\mathrm{m}}+l_{\mathrm{s}}$. We divided the observed release areas into the three different categories: (1) smooth terrain with long grass, (2) smooth terrain with short grass or shrubs, and (3) stepped or rocky terrain with shrubs (Table 3). Friction values of $0.1 \leq \mu_{\mathrm{m}} \leq 0.5$ were tested. A lower ground friction of the observed events is indicated if the length $l_{\mathrm{m}}+l_{\mathrm{S}}$ of the three terrain and vegetation categories is lower than the model calculation curves in Fig. 10. We found release areas with smooth terrain and long grass below the $\mu_{\mathrm{m}}=0.1$ curve, whereas smooth terrain with shrubs or short grass was mostly $(87 \%)$ above the $\mu_{\mathrm{m}}=0.1$ curve. $92 \%$ of rocky or stepped terrain with shrubs 
Table 3. Vegetation and terrain combined into three categories. The least roughness was observed for smooth terrain with long grass and the roughest surface was observed when stepped or rocky terrain was covered with shrubs. The second category was smooth terrain covered with short upright grass or shrubs.

\begin{tabular}{llll}
\hline Terrain + vegetation & $\begin{array}{l}\text { Smooth }+ \\
\text { long grass }\end{array}$ & $\begin{array}{l}\text { Smooth + short } \\
\text { grass or shrubs }\end{array}$ & $\begin{array}{l}\text { Stepped or } \\
\text { rocky + shrubs }\end{array}$ \\
\hline Number of avalanches & 31 & 23 & 13 \\
Mean $\alpha\left(^{\circ}\right)$ & 35 & 39 & 40 \\
Mean $l_{\mathrm{g}}(\mathrm{m})$ & 27 & 27 & 42 \\
Mean $h_{\mathrm{V}}+h_{\mathrm{t}}(\mathrm{m})$ in autumn & 0.30 & 0.33 & 0.54 \\
Mean $h_{\mathrm{v}}+h_{\mathrm{t}}(\mathrm{m})$ in winter & 0.20 & 0.22 & 0.41 \\
\hline
\end{tabular}

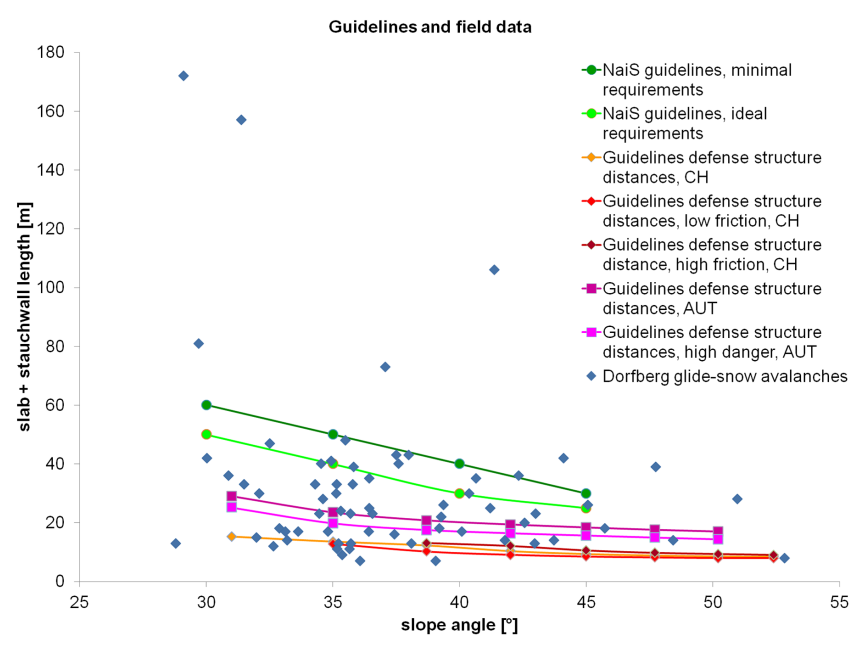

Figure 11. Comparison of guidelines with Dorfberg data. Note that most of the Dorfberg glide-snow avalanches had longer slab lengths and released on steeper slopes than proposed by the defense structure guidelines of Switzerland. In contrast, forest gaps with slope angles and lengths in accordance with the Swiss guidelines on sustainable management of protective forests (NaiS) would not have hindered avalanche formation in a lot of cases on the Dorfberg.

was above the $\mu_{\mathrm{m}}=0.3$ curve. The same analysis was performed for vegetation cover only. While release areas with long grass are found even below the $\mu_{\mathrm{m}}=0.1$ curve, $86 \%$ of all other vegetation types are above the $\mu_{\mathrm{m}}=0.2$ curve.

Guidelines on defense structure distances and forest gap sizes were formulated in Switzerland and Austria to prevent avalanches from releasing. We compared our observations with these guidelines to check on their performance. Guidelines on technical avalanche defense in Switzerland distinguish between different ground roughnesses and assume friction parameter values of $0.5 \leq \mu_{\mathrm{d}} \leq 0.6$. For the same slope angle, this variation leads to a change in the allowable slab length of a maximum of $3 \mathrm{~m}$. The values for slab length and slope angle for small snow depths $(1.5 \mathrm{~m})$ are in the range of almost all events on the Dorfberg of the 2011-2013 winters (Fig. 11). Deviations due to smooth or rough surfaces are small. Guidelines in Austria that do not distinguish between

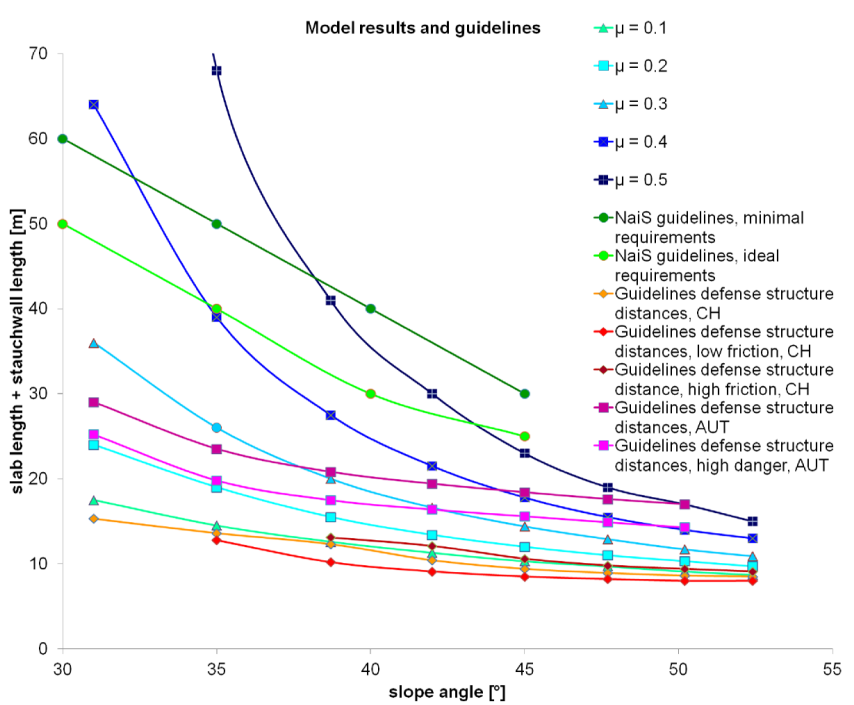

Figure 12. Comparison of guidelines with model results. Model calculations with friction values $\mu_{\mathrm{m}}=0.1$ correspond to the technical guidelines for avalanche prevention bridges. Maximum forest gap sizes proposed by the Swiss guidelines on sustainable forest management (NaiS) are appropriate for low slope angles and high friction.

different snow depths recommend larger distances between defense structures.

In contrast, most of the events on the Dorfberg are below the tolerable forest gap sizes. Lower slope angles and shorter slab lengths than proposed in the guidelines are sufficient to allow the release of glide-snow avalanches, especially when assuming a smooth surface.

We then compared the guideline values with the model results, and found a good correspondence when comparing the technical guidelines for defense structures and stauchwall model results with low friction, i.e., for friction values $\mu_{\mathrm{m}}=0.1$. This indicates that the guidelines assume low friction values, which is essential for the safe design of supporting structures. However, for higher friction values, the stauchwall model is more sensitive to the slab length and slope angle. Thus, for high friction values, we can devise slopes that are stable for slope angles up to $35^{\circ}$. The technical guidelines are again conservative, since they do not assume such high friction values. In comparison, the correspondence between the forest management recommendations and the model results was poor. This indicates that the guidelines are not consistent for the same ground roughness and slope angle (Fig. 12). The calculated maximum slab length for $\mu_{\mathrm{m}}=0.4$ and slope angle $\alpha=35^{\circ}$ corresponds to the guideline values for gap sizes under ideal conditions. However, the model results for lower slope angles overestimate the guideline values and underestimate the guideline values for high slope angles. Moreover, the forest guidelines are appropriate for low slope angles and high friction, but appear to miscalculate the acceptable gap length in steep terrain. 


\section{Conclusions}

In this study, we quantified the effect of ground roughness on glide-snow avalanche release with data on the typical vegetation cover and topographical characteristics of 101 release areas. Additionally, we employed a physical model that accounts for stauchwall mechanics and predicts failure or resistance depending on the slab length, snow depth, snow density and basal friction. We defined a critical strain rate that in turn defines the maximum slab length and slope angle allowable to prevent glide-snow avalanche release. The material parameters elasticity $E_{\mathrm{m}}, E_{\mathrm{k}}$ and viscosity $\eta_{\mathrm{m}}, \eta_{\mathrm{k}}$ were kept constant. The model results indicate a strong dependence of maximum slab length and slope angle on the Coulomb friction $\mu_{\mathrm{m}}$ of the snow on the ground, which we were able to quantify by comparing the model results with our observations.

Our field study revealed that glide-snow avalanches release on grass or shrubs and on smooth, stepped or rocky terrain. The release angle and observed slab length depend on the vegetation and terrain. We were able to define three roughness categories that have different characteristic vegetation and terrain heights. On the one hand, smooth terrain with long grass has the least roughness, and the release of avalanches is possible on relatively flat slopes with short slab lengths. On the other hand, avalanches release on stepped or rocky terrain with shrubs only if the slope is steep and long. Snow depth plays an important role, as vegetation is compressed by the snow's weight, and therefore the friction is lowered significantly. While long grass is compressed with a small load, for shrubs to be pressed together, a higher snow cover is needed.

We were able to draw conclusions about the Coulomb friction of the snow-soil interface by comparing the field data with stauchwall model calculations. Assuming stauchwall strength to be the crucial factor in glide-snow avalanche release, we selected data of release areas where the presence of a stauchwall could be expected. We defined approximate friction values $\mu_{\mathrm{m}}$ for categories "smooth terrain with long grass" $\left(\mu_{\mathrm{m}}=0.1\right)$, "smooth terrain with short grass or shrubs" $\left(\mu_{\mathrm{m}}=0.2\right)$ and "stepped or rocky terrain with shrubs" $\left(\mu_{\mathrm{m}}=0.4\right)$. These values represent the minimum Coulomb friction for a wet snow-soil interface that leads to glide-snow avalanche formation. They are slightly lower than the values Leitinger et al. (2008) found for abandoned meadows, but in the same range as the values In der Gand and Zupančič (1966) estimated for wet grass. These values are in good agreement with previous studies, and indicate that meltwater is the crucial factor leading to glide-snow avalanches. In contrast, the friction values proposed in the Swiss guidelines on artificial avalanche defense structures $\left(0.5 \leq \mu_{\mathrm{d}} \leq 0.6\right)$ are questionable if we assume snow gliding on wet smooth soil. We expect the friction $\mu_{\mathrm{m}}$ to depend on terrain, vegetation cover and the wetness of the snow-soil interface, and therefore to cover a wide range of values $(0.1$ $\left.\leq \mu_{\mathrm{m}} \leq 1.0\right)$.

Guideline values for the distance of technical defense structures are in accordance with the data and the model calculations for low friction $\left(\mu_{\mathrm{m}}=0.1\right)$. Our results indicate that the release of glide-snow avalanches in between defense structures is unlikely. According to the Swiss guidelines, the distance between structures depends strongly on the assumed maximum snow depth. A greater snow depth leads to larger spacing. This is in accordance with our model calculations. However, this conclusion is based on the model assumption that higher snow covers are associated with longer stauchwall lengths. This assumption is supported by the field observations. The important relationship between snow cover height and structure spacing is central to ongoing discussions (Matsushita et al., 2012). Austrian guidelines do not account for varying snow depths; therefore, relatively large distances are recommended for small snow depths (Austrian Standard Institute, 2011). Guidelines on maximum forest gap sizes in Switzerland fit our observations and calculations only if the ground roughness is relatively high. For $\mu_{\mathrm{m}} \approx 0.4$, the guidelines ensure safety for slope angles below $35^{\circ}$. To prevent avalanche formation on such slopes, we assume that a terrain roughness corresponding to stepped or rocky terrain and dwarf shrubs (e.g., Vaccinium vaccinium or Rodhodendron ferrugineum) is necessary in addition to the minimal required forest cover characteristics given in the existing guidelines. Higher slope angles would even require a higher terrain roughness corresponding to strong lignified shrubs, stumps or piles of dead wood to hinder gliding. To leave logs of dead wood and high stumps in clearings is already often considered to be a safety measure in silvicultural management (Frehner et al., 2005; BAFU, 2008). This study underlines the importance of these measures, in particular for protective forests with low roughness and little ground vegetation.

Acknowledgements. The authors thank the Austrian Research Center for Forests for organizing the meeting on forest protection and natural hazards in January 2014. We profited from interesting presentations and conversations rich in content on the topic of this work. Professor Kurosch Thuro, Chair of Engineering Geology at the Technical University of Munich, supported our work and made it possible. This research was funded by the Bavarian Environment Agency.

Edited by: P. Tarolli

Reviewed by: J.-T. Fischer and two anonymous referees 


\section{References}

Austrian Standard Institute: ONR 24806 - Permanent technical avalanche protection - Design of structures, Vienna, 2011.

BAFU: Sturmschaden-Handbuch, Vollzugshilfe für die Bewältigung von Sturmschadenereignissen von nationaler Bedeutung im Wald, 3. überarbeitete Auflage, Bundesamt für Umwelt, Bern, 2008.

Bartelt, P., Feistl, T., Bühler, Y., and Buser, O.: Overcoming the stauchwall: viscoelastic stress redistribution and the start of fulldepth gliding snow avalanches, Geophys. Res. Lett., 39, L16501, doi:10.1029/2012GL052479, 2012.

de Quervain, M.: Wald und Lawinen, in: Proceedings of the IUFRO Seminar "Mountain Forests and Avalanches", Davos, Switzerland, 219-239, 1979.

de Quervain, M. and Salm, B.: Lawinenverbau im Anbruchgebiet: Kommentar zu den Richtlinien für den permanenten Stützverbau vom Februar 1961, Eidg. Inspektion für Forstwesen, 1963.

Dreier, L.: Einfluss von Wetter und Gelände auf Gleitschneelawinen, M.S. thesis, Friedrich-Alexander-Universität, ErlangenNürnberg, 2013.

Dreier, L., Mitterer, C., Feick, S., and Harvey, S.: The influence of weather on glide-snow avalanches, in: Proceedings, International Snow Science Workshop, France, Grenoble, 2013.

Fiebiger, G.: Ursachen von Waldlawinen im Bereich der nordöstlichen Randalpen und ihre Behandlung durch foresttechnische Massnahmen, Ph.D. thesis, Universität für Bodenkultur, Wien, 1978.

Frehner, M., Wasser, B., and Schwitter, R.: Nachhaltigkeit und Erfolgskontrolle im Schutzwald, Wegleitung für Pflegemassnahmen in Wäldern mit Schutzfunktion, Vollzug Umwelt, Bundesamt für Umwelt, Wald und Landschaft, Bern, 564, 2005.

Gubler, H. and Rychetnik, J.: Effects of forests near timberline on avalanche formation, Snow, Hydrology and Forests in High Alpine Areas, 205, 19-38, 1991.

Häfeli, R.: Kriechen und progressiver Bruch in Schnee, Boden, Fels und Eis, Schweizerische Bauzeitung, 85, 1-9, 1967.

Höller, P.: Snow gliding and avalanches in a south-facing larch stand, IAHS Publ., 270, 355-358, 2001.

Höller, P.: Untersuchungen zum Schneegleiten in einem Lärchenwald nahe der Waldgrenze, in: BFW-Berichte, Bundesministerium für Land- und Forstwirtschaft Umwelt und Wasserwirtschaft, 2004.

Höller, P.: Snow gliding and glide avalanches: a review, Nat. Hazards, 71, 1259-1288, 2014.
Höller, P.: On the identification of snow gliding areas and planning of control measures to protect high-altitude afforestations, Allgemeine Forst- und Jagdzeitung, 183, 94-100, 2012.

Imbeck, H.: Lawinenbildung im Wald und deren Wirkung im Raum Davos, Tech. rep., WSL Institute for Snow and Avalanche Research SLF, 1984.

Imbeck, H. and Meyer-Grass, M.: Waldlawinen am Gugelberg, Schweizer Zentrales Forstwesen, 139, 145-152, 1988.

In der Gand, H. and Zupančič, M.: Snow gliding and avalanches, IAHS-AISH Publ., 69, 230-242, 1966.

Lackinger, B.: Stability and fracture of the snow pack for glide avalanches, Int. Assoc. Hydrol. Sci. Publ., 162, 229-240, 1987.

Leitinger, G., Höller, P., Tasser, E., Walde, J., and Tappeiner, U.: Development and validation of a spatial snow-glide model, Ecol. Model., 211, 363-374, 2008.

Margreth, S.: Lawinenverbau im Anbruchgebiet, Technische Richtlinie als Vollzugshilfe, Bundesamt für Umwelt, Bern, 2007.

Matsushita, H., Matsuzawa, M., and Nakamura, H.: Possibility of increasing the slope distance between avalanche prevention bridges, in: Proceedings of the International Snow Science Workshop ISSW, Anchorage, Alaska, 2012.

McClung, D.: Creep and the snow-earth interface condition in the seasonal alpine snowpack, IAHS-AISH Publ., 114, 236-248, 1975.

Meyer-Grass, M. and Schneebeli, M.: Die Abhängigkeit der Waldlawinen von Standorts-, Bestandes-, und Schneeverhältnissen, in: Internationales Symposion Interpraevent - Bern, 1992.

Mitterer, C., Hirashima, H., and Schweizer, J.: Wet-snow instabilities: comparison of measured and modelled liquid water content and snow stratigraphy, Ann. Glaciol., 52, 201-208, 2011.

Newesely, C., Tasser, E., Spadinger, P., and Cernusca, A.: Effects of land-use changes on snow gliding processes in alpine ecosystems, Basic Appl. Ecol., 1, 61-67, 2000.

Scapozza, C. and Bartelt, P.: Triaxial tests on snow at low strain rate, Part II, Constitutive behaviour, J. Glaciol., 49, 91-101, 2003.

Schneebeli, M. and Bebi, P.: Snow and avalanche control, edited by: Burley, J., Evans, J., and Youngquist, J. A., Encyclopedia of Forest Sciences, Elsevier, 397-402, 2004.

van Herwijnen, A. and Simenhois, R.: Monitoring glide avalanches using time-lapse photography, in: International Snow Science Workshop ISSW, 2012.

Von Moos, M., Bartelt, P., Zweidler, A., and Bleiker, E.: Triaxial tests on snow at low strain rate, Part I. Experimental device, J. Glaciol., 49, 81-90, 2003.

Weir, P.: Snow Avalanche Management in Forested Terrain, B. C. Government Publication Services, 2002. 